\title{
O PAPEL DAS INSTITUIÇÕES SOCIAIS ANTE O DESAFIO DE INOVAR OS PROCESSOS DE GESTÃO TERRITORIAL: UMA ANÁLISE COMPARATIVA ENTRE O GRANDE ABC PAULISTA E OS MUNICÍPIOS DO EIXO DUTRA.
}

THE ROLE OF SOCIAL INSTITUTIONS AT THE CHALLENGE TO INNOVATE THE TERRITORIAL MANAGEMENT PROCESSES: A COMPARATIVE ANALYSIS OF THE GREATER ABC REGION AND THE MUNICIPALITIES OF DUTRA AXIS.

\section{Recebido: 21/05/2015 - Aprovado: 9/10/2015 - Publicado: 1/12/2015 Processo de Avaliação: Double Blind Review}

Wiliam Retamiro ${ }^{1}$

Mestre em Planejamento e Desenvolvimento Regional- Universidade Taubaté- UNITAU wretamiro@yahoo.com.br

\section{RESUMO}

O presente trabalho objetiva debater o papel das instituições sociais universais como ferramenta essencial para transformar uma sociedade por meio de uma nova visão econômica. Desenvolvido por uma metodologia bibliográfica e documental, este artigo tece uma análise de como as instituições sociais, sendo o Estado, a economia e universidade podem interferir na realidade socioeconômica de um território, outrora imutável quanto a sua realidade para uma nova perspectiva de mutação promissora. Dialoga-se acerca do desenvolvimento por intermédio da libertação intelectual promovida pelo acesso ao conhecimento. Verifica-se então, que as instituições sociais universais atuam aquém desta perspectiva. Utilizando da comparação entre as regiões do Grande ABC e do Eixo Dutra, questiona-se, então, a possibilidade do indivíduo se conscientizar de sua condição atual, com uma visão crítica acerca de uma situação desfavorável para a possibilidade de mutação por meio do entendimento com a elucidação do entender econômico, proporcionando a inovação de projetos de governança territorial.

Palavras-chave: 1. Desenvolvimento Regional; 2. Instituições Sociais, 3. Governança Territorial; 4. Planejamento Territorial.

\section{ABSTRACT}

This paper aims to discuss the role of universal social institutions as an essential tool to transform society through a new economic vision. Developed by a bibliographical and documentary methodology, this article presents an analysis of how social institutions, and the state, the economy and university may interfere with the economic reality of a territory once immutable as your reality for a new perspective on promising mutation. If dialogue-

\footnotetext{
${ }^{1}$ Autor para correspondência- Instituto Tecnológico da Aeronaunática- ITA Avenida Granadeiro Guimarães, 270- bairro Centro- São Paulo -SP, 12020-130.
} 
about development through intellectual liberation promoted by access to knowledge. It appears then that the universal social institutions operate below this perspective. Using the comparison between the regions of the Greater ABC and Dutra Axis question is then the possibility of the individual is aware of his present condition, with a critical view about an unfavorable situation for the possibility of mutation through understanding with the elucidation of economic understanding, providing the innovation of territorial governance projects.

Keywords: 1. Regional development; 2. Social institutions 3. Territorial Governance; 4. Physical Planning.

\section{INTRODUÇÃO}

O processo de descentralização autônoma das grandes regiões metropolitanas, decorrente do esgotamento de recursos econômicos e naturais, que impactam diretamente na sociedade, ocorre, mesmo que de forma velada.

Diz-se de forma autônoma, devido ao êxodo das empresas que outrora se localizavam nas regiões metropolitanas, mas que por motivos dos altos custos operacionais (logística, mão de obra, os custos intangíveis das grandes cidades, etc.), se veem na condição de buscar novos terminais para realizarem sua atracagem duradoura.

No tocante ao esgotamento, este fato é identificado quando se observa a mudança na rota dos investimentos privados, à busca de alocações em regiões nas quais o salário médio seja inferior ao das grandes cidades, estas, muitas vezes já exauridas da oferta de mobilidade urbana, acesso dificultado aos serviços públicos minimamente qualitativos, bem como de demais infraestruturas necessárias para a manutenção do desenvolvimento, denota a renúncia dos investidores. Tal renúncia, devidamente associada à forma autônoma de busca por novos territórios, expressa a ausência de políticas públicas inovadoras capazes de reestruturar a vida concomitante das dimensões da sustentabilidade.

Em um cenário fadado ao ostracismo, as cidades-regiões receptoras desses investimentos sofísticos, tendem a serem meras reprodutoras das ações desconexas das instituições sociais existentes nas grandes regiões metropolitanas, onde já se observa a significativa disparidade econômica, política e cultural, o que eleva ainda mais o obstáculo de integração regional, já perceptível na medida em que os municípios com maior arrecadação retém a redistribuição de parte de sua receita, decorrente da ausência de racionalização dos investimentos baseados em planejamento territorial.

Este trabalho visa debater o papel de algumas instituições sociais universais, ante o desafio de propor uma governança metropolitana inovadora, de cunho alternativo, a fim de suprir a ausência do Estado desenvolvimentista na produção do espaço urbano-regional.

Com o intuito de lucubrar sobre este tema, o presente trabalho está organizado a seguir em cinco seções. A primeira seção contextualiza o embasamento legal da constituição das Regiões Metropolitanas. Aborda a alternância da designação de um regime centralista e autocrático para um sistema democrático, mas negligente. 
A seguir, explana as semelhanças existentes entre duas sub-regiões, as quais, embora tenham três décadas de diferença entre suas respectivas promulgações, as RM's possuem similaridades no aspecto socioeconômico, especialmente, no tocante a geração de riqueza regional e demandas sociais. Ainda, a versão de investimentos privados de uma para a outra, corroborando para a descentralização autônoma, decorrente da carência de ações públicas inovadoras.

Ademais, com o arcabouço preliminarmente estruturado, discorrer-se-á acerca do foco deste trabalho, que é o papel das instituições sociais, ao que tange sua relevância na formação, planejamento e execução de propostas alternativas para uma governança metropolitana inovadora.

$\mathrm{Na}$ conclusão, se tece considerações com vistas a suplantar um modelo de governança metropolitana obsoleta, a fim de se perfazer uma nova práxis.

\section{A CONSTITUIÇÃO E AS EXPECTATIVAS ACERCA DAS REGIÕES METROPOLITANAS}

No Brasil, as Regiões Metropolitanas (RM’s) começaram a ser implementadas em 1973, durante o regime militar, em atendimento à Constituição de 1967, mais especificamente, na Lei Complementar 14, a qual instituiu as RM's de São Paulo, Belo Horizonte, Porto Alegre, Recife, Salvador, Curitiba, Belém e Fortaleza (Brasil, Lcp. № 14, 1973, art.1 ${ }^{\circ}$ ). Com a promulgação da Constituição de 1988, fora transferida aos Estados a responsabilidade pela criação, bem como a sua organização.

As RM's consistem em arranjos administrativos e políticos, com vistas ao estudo e desenvolvimento de políticas públicas que atendam a demanda regional, sob a ótica e participação do tripé da gestão pública (municipal, estadual e federal), a fim do desenvolvimento e da cooperação intergovernamental para o atendimento do interesse comum (LAGO, 2000).

De acordo com o censo de 2010 (IBGE, 2010), conforme exposto na tabela1, trinta e cinco eram as RM's e as Regiões Integradas de Desenvolvimento Econômico (RIDE's), três. Esta última, consiste em regiões metropolitanas criadas por legislação federal específica e se situam em mais de uma unidade federativa, que delimita os municípios que a integram e fixa as competências assumidas. Observa-se que tanto para as RM's, como para as RIDE's, há ações relacionadas ao planejamento, organização e execução das funções públicas de interesse comum, com vistas ao desenvolvimento socioeconômico, sendo: sistema de saúde, saneamento, habitação, meio ambiente, defesa civil e transporte.

Contudo, apesar da expansão das RM/RIDE, segundo Maricato (2011, pag. 03) é precária a diversidade de critérios para a definição destas, pois, tais são convencionadas a cada Estado da federação. Se no decorrer do período ditatorial, tal definição era realizada por meio de imposição de lei federal, logo, de característica impositiva; após a Constituição de 1988, de forma descentralizada e democrática, os Estados, por meio de seus próprios critérios definem as RM's, porquanto, caracteriza-se a autonomia municipal, privilegiando o 
desenvolvimento urbano. Porém, nenhuma das formas proporcionou resultados satisfatórios, conforme corrobora Sol Garson:

Numa perspectiva mais ampla, no entanto, a gestão metropolitana ganhou complexidade adicional, entre outros fatores, em virtude de efeitos perversos decorrentes da grande autonomia municipal após a constituição de 1988: a competição fiscal, o neolocalismo e as dificuldades adicionais de coordenação interinstitucional (GARSON, 2009).

Todavia, em que pese os problemas decorrentes da flexibilidade em se criar novas RM's, há em contrapartida, os benefícios direcionados aos municípios integrantes destas, devidamente amparados pela mesma Lcp 14 em seu artigo $6^{\circ}$ :

art. $6^{\circ}$ - Os Municípios da região metropolitana, que participarem da execução do planejamento integrado e dos serviços comuns, terão preferência na obtenção de recursos federais e estaduais, inclusive sob a forma de financiamentos, bem como de garantias para empréstimos (Brasil, Lcp. No 14, 1973, art. $1^{\circ}$ ).

A preferência na obtenção de recursos citada na Lei refere-se especialmente ao provimento de apoio financeiro na realização de ações que atendam as demandas socioespaciais, devidamente articuladas pelo apoio político. Dentre os benefícios, destacamse a ampliação da disponibilidade de serviços públicos, os quais dinamizam o mercado de trabalho aperfeiçoando a infraestrutura existente na região. Contudo, age de forma desfavorável, a elevação do custo de vida, a vulnerabilidade social, o esgotamento da infraestrutura viária, os malefícios ambientais, dentre outros.

Esta dicotomia, entre os benefícios e as consequências da criação das RM's, oriunda da descentralização e da ausência de critérios claros para a sua concepção, faz com que ocorra uma subdivisão em cada região, decorrente da disparidade existente entre os municípios, principalmente ao que tange os aspectos socioeconômicos. Com vistas a estas perspectivas, analisar-se-ão duas subdivisões de distintas RM's, sendo a Região do Grande ABC, integrante da Região Metropolitana de São Paulo (RMSP) e, as cidades do Eixo Dutra, integrantes da Região Metropolitana do Vale do Paraíba e Litoral Norte (RMVPLN).

\section{ANÁLISE COMPARATIVA: REGIÃO DO GRANDE ABC E EIXO DUTRA}

Neste estudo, com o intuito de analisar o processo de evolução das instituições sociais, bem como os seus papéis ante a sociedade, far-se-á a seguir, uma análise comparativa de duas subdivisões de RM's, sendo, a Região do Grande ABC, integrante da RMSP; e do Eixo Dutra, que integra a RMVPLN. 


\subsection{CONTEXTUALIZAÇÃO DA REGIÃO DO GRANDE ABC}

Primeiramente, o objeto de análise se dará com a Região do Grande ABC, a qual é constituída pelos municípios de Santo André, São Bernardo do Campo, São CAeano do Sul, Diadema, Mauá, Ribeirão Pires e Rio Grande da Serra; os quais, juntamente com mais outros 32 municípios, formam a RMSP.

Foram os imigrantes quem iniciaram a história econômica do Grande ABC, sendo a proximidade com a capital, um fator determinante na ocupação urbana, tal como os investimentos públicos e privados contribuíram para a reurbanização da região. No aspecto econômico, a Região do Grande $\mathrm{ABC}$ é caracterizada como polo da indústria automobilística no país, o qual perfaz importantes complexos industriais, que em análise conjuntural à participação das atividades do setor de serviços e comércio varejista, representa o quinto maior mercado consumidor do Brasil, condizente com o elevado grau de urbanização, cuja população de 2,6 milhões de habitantes está distribuída em um território de $828 \mathrm{~km}^{2}$.

Sua malha logística é composta principalmente por uma rede ferroviária, as rodovias Anchieta e Imigrantes, que ligam a capital a Região Metropolitana da Baixada Santista e, recentemente o Trecho Sul do Rodoanel Mário Covas. Contém ainda, espaços e reservas naturais que faz da Região do Grande $\mathrm{ABC}$, um relevante reservatório hídrico do Estado de São Paulo (AGENCIA GABC, 2014).

\section{Figura 1: Região Metropolitana de São Paulo - Região Grande ABC}

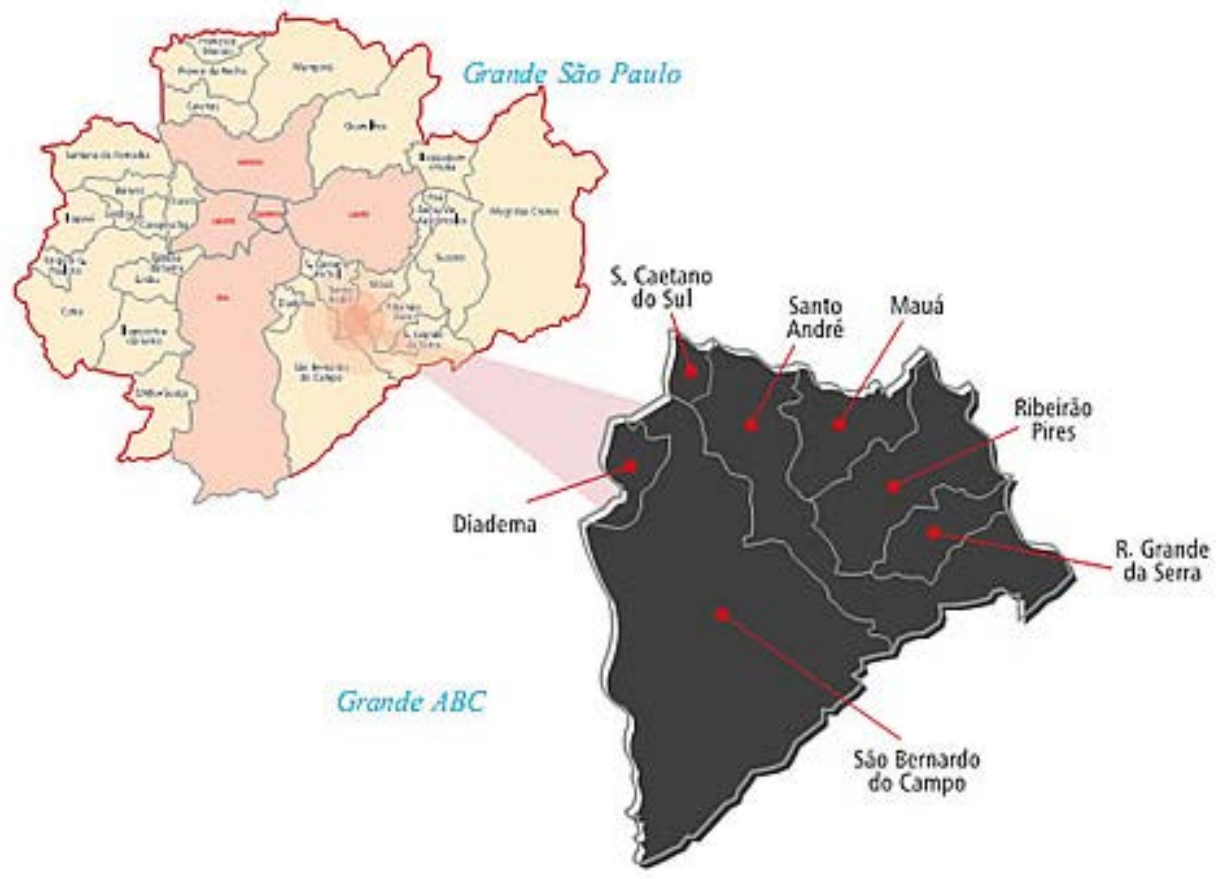

Fonte: Agencia de Desenvolvimento Econômico do Grande ABC, 2014. 


\subsection{CONTEXTUALIZAÇÃO DO EIXO DUTRA}

O outro terrtório da pesquisa está baseado na Região Metropolitana do Vale do Paraíba e Litoral Norte, a qual foi criada em janeiro de 2012, conforme a Lcp 1.166, se constitui por 39 municípios divididos em cinco sub-regiões, conforme figura 1. A região do Vale do Paraíba Paulista iniciou sua expansão econômica com a exploração da cultura cafeeira. Porém; nos anos 30, a cafeicultura entrara em sua fase de decadência na região fazendo com que ocorresse a migração da zona rural para a urbana, em busca de emprego nas indústrias (RICCI, 2006, p. 35-42).

No bojo da política nacionalista que inundava o Brasil, a partir da década de 1940, embuído da ação keynesiana desenvolvimentista, principalmente nas questões relacionadas à tecnologia, foi o Vale do Paraíba Paulista, foco para implementação de uma infraestrutura industrial, acompanhada pela formação de mão de obra qualificada (a qualificação de mão de obra não fora fator sinequanon na Região do Grande $A B C$ ). A tomada de decisão por parte do governo em implementar na região indústrias de base tecnológica, tinha como objetivo ampliar a política de substituições das importações (LUZ, MINARI e SANTOS, 2010, p. 72-73).

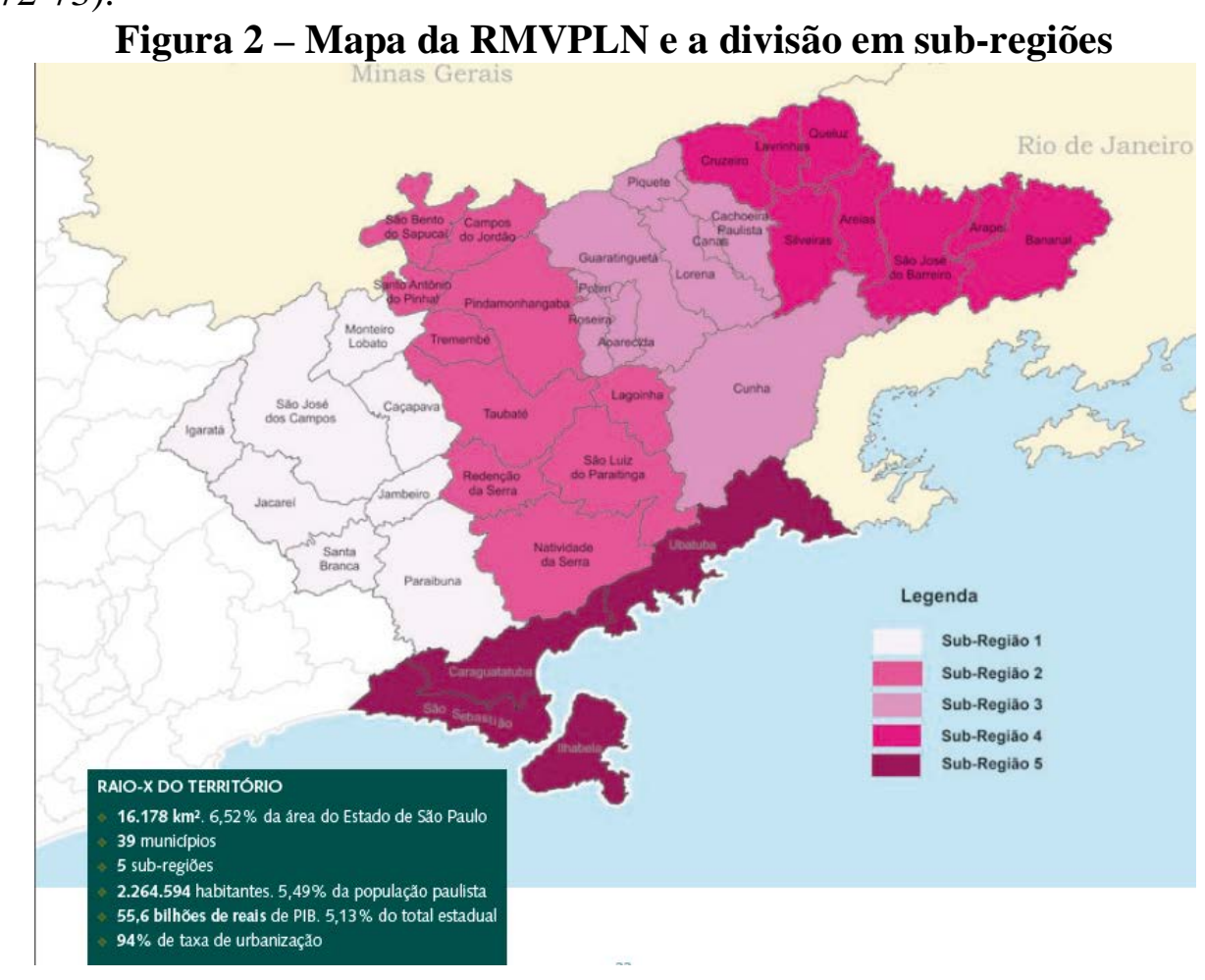

Fonte: Secretaria de Desenvolvimento Metropolitano de São Paulo, 2012

A localização geográfica privilegiada se dá ao fato de estar situado entre as duas principais regiões metropolitanas do país - São Paulo e Rio de Janeiro - interligadas pela rodovia Presidente Dutra, inaugurada em 1951, o que possibilitou que os investimentos na região, tanto governamentais quanto privados, se elevassem, acasionando assim, o desenvolvimento regional. A figura 3 demonstra que houve uma clara caracterização dos setores industriais tecnológicos na região, sendo, além do automobilístico, o aeroespacial. 
Na tabela 1, averigua-se a cronologia de implantação das principais indústrias formando seus respectivos clusters.

A formação do cluster automobilístico se inicia ao final da década de 1950, mais especificamente com a Willys do Brasil, em 1958 na cidade de Taubaté, onde posteriormente instalaram-se a Ford (1967) e a Volkswagen (1973), todas oriundas de empresas transnacionais, cujas primeiras unidades estavam situadas no Região do Grande ABC. Neste ínterim, mais especificamente em 1959, instalou-se, também na cidade de São José dos Campos, a General Motos do Brasil. A formação do cluster automobilísitco no Vale do Paraíba, deve-se, além da posição geográfica privilegiada, ao fato da necessidade de expansão do espaço físico para atendimento de uma demanda emergente, bem como, uma forma de se desvincular da pressão sindical existente com maior ênfase na Região do Grande ABC.

\section{Figura 3: Formação dos clusters aeroespacial e automobilístico}

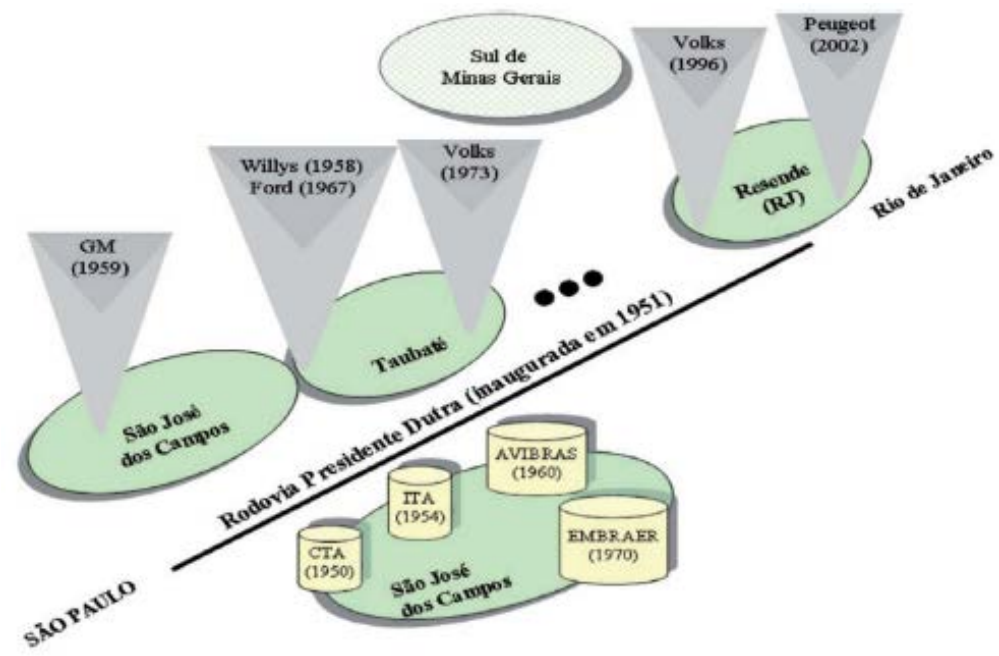

Fonte: LUZ, MINARI e SANTOS, 2010, p. 72

Coube a cidade de São José dos Campos, receber o investimento que dependia tão somente da ação da federação, por se tratar de ser este um investimento estratégico e também de alto valor monetário, o cluster aeroespacial. Tal cluster teve sua introdução planejada em 1947, constituído pelos núcleos tecnológicos CTA, impementado em 1950 e o ITA em 1954, com o objetivo de construir uma estrutura aeroespacial produtiva, destinandose à formação de mão de obra qualificada para o setor. Com o apoio dos núcleos tecnológicos, deu-se em 1970, a criação da EMBRAER, empresa estatal ${ }^{2}$, onde fora concebido o avião Bandeirante, conferindo a empresa, qualificação para se dedicar à pesquisa, desenvolvimento e fornecedores para o setor.

\footnotetext{
${ }^{2}$ A EMRAER fora privatizada em 1994 (Governo FHC), por R\$ 154,1 milhões - valores atualizados adquirida pelo grupo Bozano Simonsen e pelos fundos Previ e Sistel.
} 
Tabela 1: Cronologia da instalação das empresas que foramaram seus respectivos cluster.

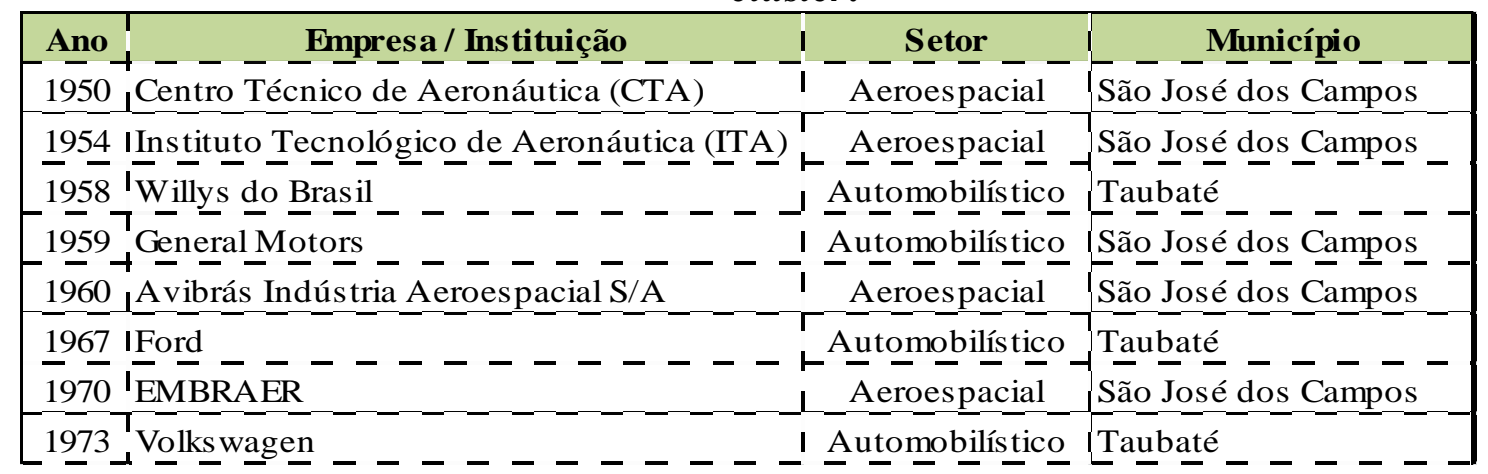

Fonte: RETAMIRO, $20 \overline{2}$.

No tocante ao ensino superior a RMVP possui significativo número de instituições públicas de ensino superior (UNESP, UNIFESP, ITA, USP, UNITAU, CEBIMar/SP, além de cinco FATEC's). Ademais, a região conta com IES particulares e ETEC's em 11 municípios.

Diante desta ação desenvolvimentista é tácita a expansão de empresas ligadas aos setores supracitados de ambas as RM's. Assim, juntamente com a expansão das empresas ligadas ao setor, ocorre concomitantemente, a elevação demográfica local, o que eleva a demanda do aparato público. Para um melhor delineamento e análise, o recorte realizado a fim de se estudar os aspectos semelhantes entre as regiões, aqui optou-se por definir os sete municípios, de cada RM, com maior Produto Interno Bruto (PIB), segundo os dados do IBGE, ano base 2010.

Seguindo este critério, as cidades da Região do Grande ABC que compõem esta pesquisa são: Santo André, São Bernardo do Campo, São Caetano do Sul, Diadema, Mauá, Ribeirão Pires e Rio Grande da Serra. As cidades da RMVP, que compem este estudo, com base no critério de maior PIB são, na maioria, os municípios que integram o denominado Eixo Dutra ${ }^{3}$ : Jacareí, São José dos Campos, Caçapava, Taubaté, Pindamonhangaba e Guaratinguetá. Ainda, conforme o critério de avaliação, se insere o município de São Sebastião, cuja atividade economica principal está relacionada aos investimentos da Petrobrás.

\footnotetext{
${ }^{3}$ Termo utilizado na publicação “Região Metropolitana do Vale do Paraíba e Litoral Norte”, da Secretaria de Desenvolvimento.
} 
Tabela 2: Principais municípios da Região do Grande ABC e Eixo Dutra (PIB-2010)

\begin{tabular}{|c|c|c|c|c|c|}
\hline & \multirow{2}{*}{\multicolumn{2}{|c|}{ População 2010}} & \multirow{2}{*}{\multicolumn{2}{|c|}{ PIB (2010) }} \\
\hline & & & & & \\
\hline Municípios & RM/Subdivisão & Quantidade & $\%$ & R\$ (milhões) & $\%$ \\
\hline São Bernardo do Campo & ABC Paulista & 765.463 & 18,72 & 36.337 .338 & 25,99 \\
\hline São José dos Campos & Eixo Rod. Dutra & 629.921 & 15,41 & 25.212 .467 & 18,03 \\
\hline Santo André & ABC Paulista & 676.407 & 16,54 & 17.664 .718 & 12,64 \\
\hline Diadema & ABC Paulista & 386.089 & 9,44 & 11.786 .624 & 8,43 \\
\hline São Caetano do Sul & ABC Paulista & 149.263 & 3,65 & 11.762 .744 & 8,41 \\
\hline Taubaté & Eixo Rod. Dutra & 278.686 & 6,82 & 9.756 .817 & 6,98 \\
\hline Mauá & ABC Paulista & 417.064 & 10,20 & 7.633.782 & 5,46 \\
\hline Jacareí & Eixo Rod. Dutra & 211.214 & 5,17 & 5.729 .981 & 4,10 \\
\hline Pindamonhangaba & Eixo Rod. Dutra & 146.995 & 3,59 & 3.781 .680 & 2,71 \\
\hline São Sebastião & Eixo Rod. Dutra & 73.942 & 1,81 & 2.892 .006 & 2,07 \\
\hline Caçapava & Eixo Rod. Dutra & 84.752 & 2,07 & 2.512 .399 & 1,80 \\
\hline Guaratinguetá & Eixo Rod. Dutra & 112.072 & 2,74 & 2.221 .384 & 1,59 \\
\hline Ribeirão Pires & ABC Paulista & 113.068 & 2,77 & 1.978.256 & 1,42 \\
\hline Rio Grande da Serra & ABC Paulista & 43.974 & 1,08 & 529.413 & 0,38 \\
\hline TOTAI & & 4.088 .910 & 100,00 & 139.799.609 & 100,00 \\
\hline
\end{tabular}

Fonte: IBGE, 2010 - elaborado pelo autor.

Em análise a tabela 2, se obtém informações que denotam o processo de incentivos respaldados pela Lcp 14. Primeiramente, a soma do PIB dos três municípios com maior valor, perfaz 56,7\%, bem como a soma da população destes mesmos municípios somam 50,7\%. Nisto, verifica-se a relação existente entre adensamento demográfico e geração de riqueza (PIB).

Ao utilizar o princípio da correlação, o qual estuda o comportamento conjunto das variáveis quantitativas, medindo o grau de associação entre estas (População e PIB), obtémse o resultado 0,91, cujo significado indica a forte correlação positiva entre estas variáveis. Ao analisar o gráfico 1, tal relação pode ser melhor percebida, quando comparados os municípios cujo PIB não ultrapassa R \$ 4 milhões, os quais somam cinco municípios dentre os quatorze selecionados, estes apresentam entre população e PIB, 14,1\% e 10,0\%, respectivamente.

Outro ponto a ser percebido, se refere ao PIB médio das cidades analisadas, cuja média anual é de R\$31.944,76. O PIB médio de R\$12,5 bilhões da Região do Grande ABC é superior em 40,8\%, em relação ao do Eixo Dutra, com R\$ 7,4 bilhões; similarmente, a média populacional do ABC é superior em 39,73\%. Contudo, ao examinar por regiões, vê-se que as cidades da Região do Grande ABC, logram o PIB per capta anual de R\$ 34.371,46, enquanto que os municípios do Eixo Dutra perfazem $\mathrm{R} \$ 33.888,75$, diferença em números relativos de apenas $1,4 \%$. Nisto, confirma-se o adensamento populacional, bem como a concentração de riqueza regional, neste caso, sendo o município de São José dos Campos, a principal motriz econômica do Eixo Dutra, haja vista, em confronto de dados com a segunda cidade da região, Taubaté, nos quesitos PIB e população, ser superior em 158\% e 126\%, respectivamente. 


\section{Gráfico 1: Correlação entre PIB x População - Região do Grande ABC e Eixo Dutra}

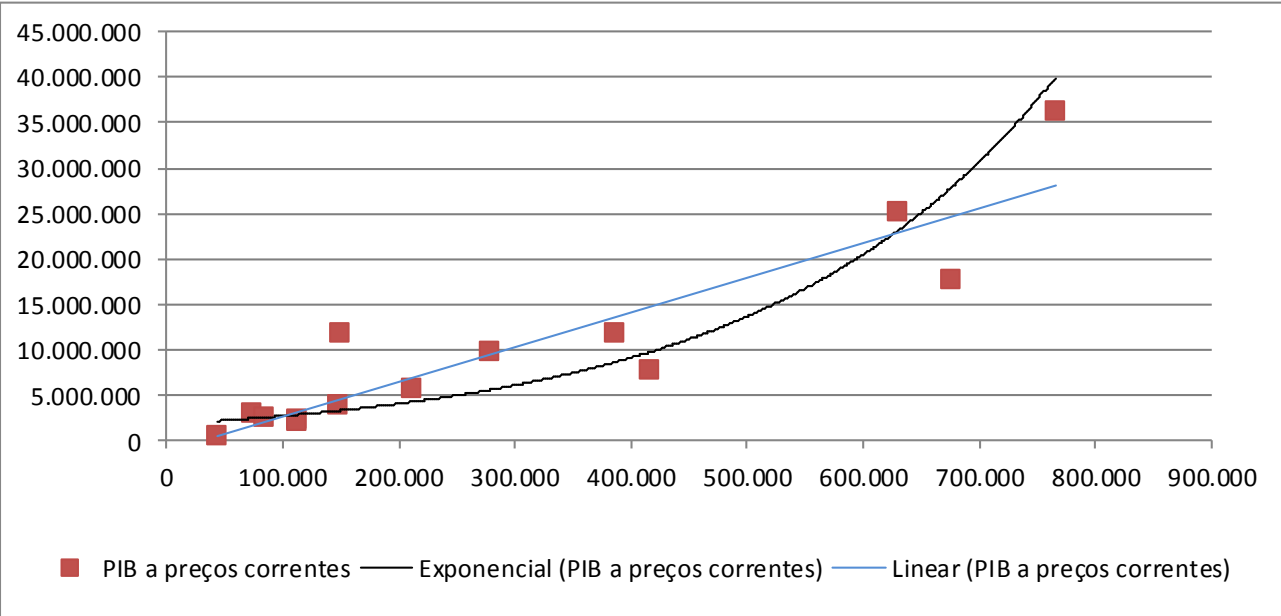

Fonte: IBGE, 2010 - elaborado pelo autor

Corrobora ainda, com esta análise, o fato do município de São José dos Campos se encontrar na segunda posição da pesquisa, no tocante ao PIB anual e, na questão demográfica ser a terceira cidade, integrando assim, os cinco municípios que se estão acima da média. Ademais, verifica-se que dentre a metade dos municípios analisados, apenas dois do Eixo Dutra se configuram com maior riqueza.

\section{Gráfico 2: PIB x População dos municípios do Região do Grande ABC e Eixo Dutra}

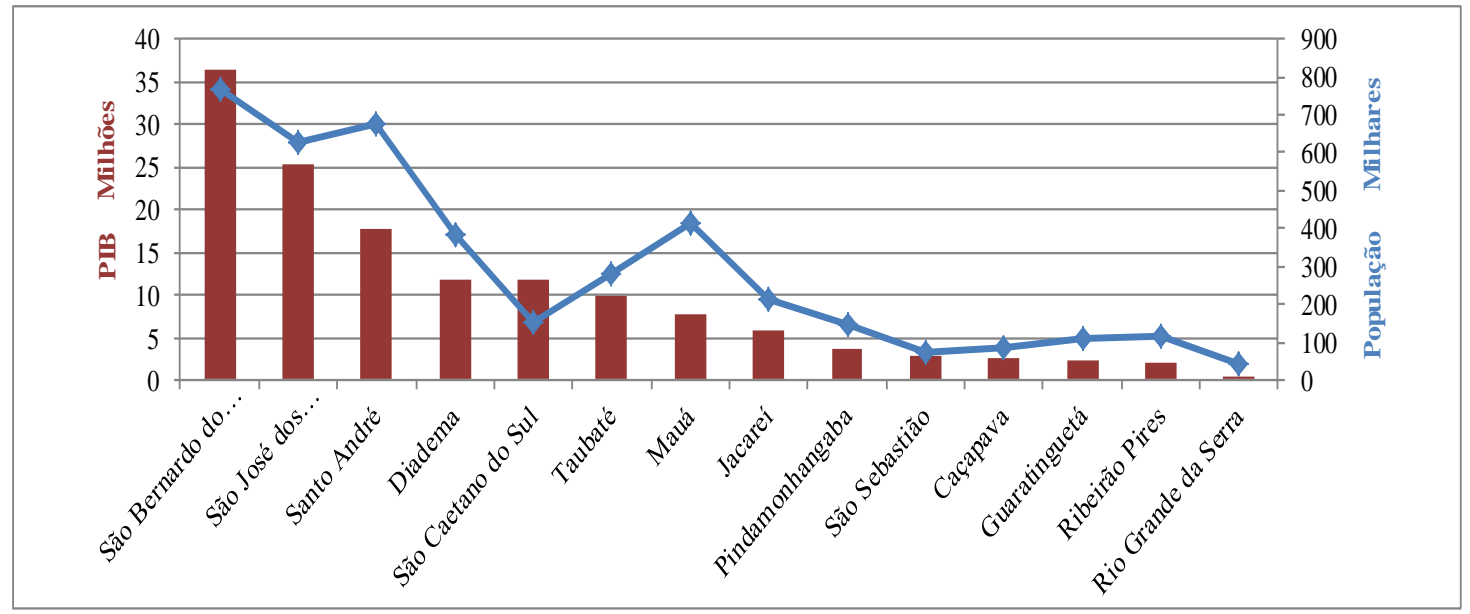

Fonte: IBGE, 2010 - elaborado pelo autor 
Para finalizar a análise socioeconômica, a qual suprirá a base para a análise do planejamento territorial, que se dará adiante neste trabalho, discorrer-se-á acerca da aferição das tendências de investimentos em ambas as regiões, com base no PIESP-SEADE ${ }^{4}$.

O gráfico 3, expressa a Pesquisa de Investimentos Anunciados no Estado de São Paulo (PIESP), que nesta análise apresenta os investimentos anunciados nas regiões objeto deste trabalho. Conforme anteriormente apresentado, a região do Região do Grande ABC fora foco de investimentos diretos estrangeiros, especialmente com o Plano de Metas, da era JK, o que possibilitou a instalação de empresas multinacionais, com ênfase no setor automobilístico. Não obstante, os municípios do Eixo Dutra foram centros para se verter investimentos, ao ponto de na primeira década do século XXI ser foco da investidura, superior a Região do Grande ABC em seis anos. Entre os anos de 2010 a 2013, os investimentos nos municípios do Eixo Dutra foram, em média, 67,39\% superior em relação à Região do Grande ABC, quando no ano de 2012 se obteve a maior diferença com 112\%.

\section{Gráfico 3: Investimentos anunciados nos municípios da Região do Grande ABC e Eixo Dutra}

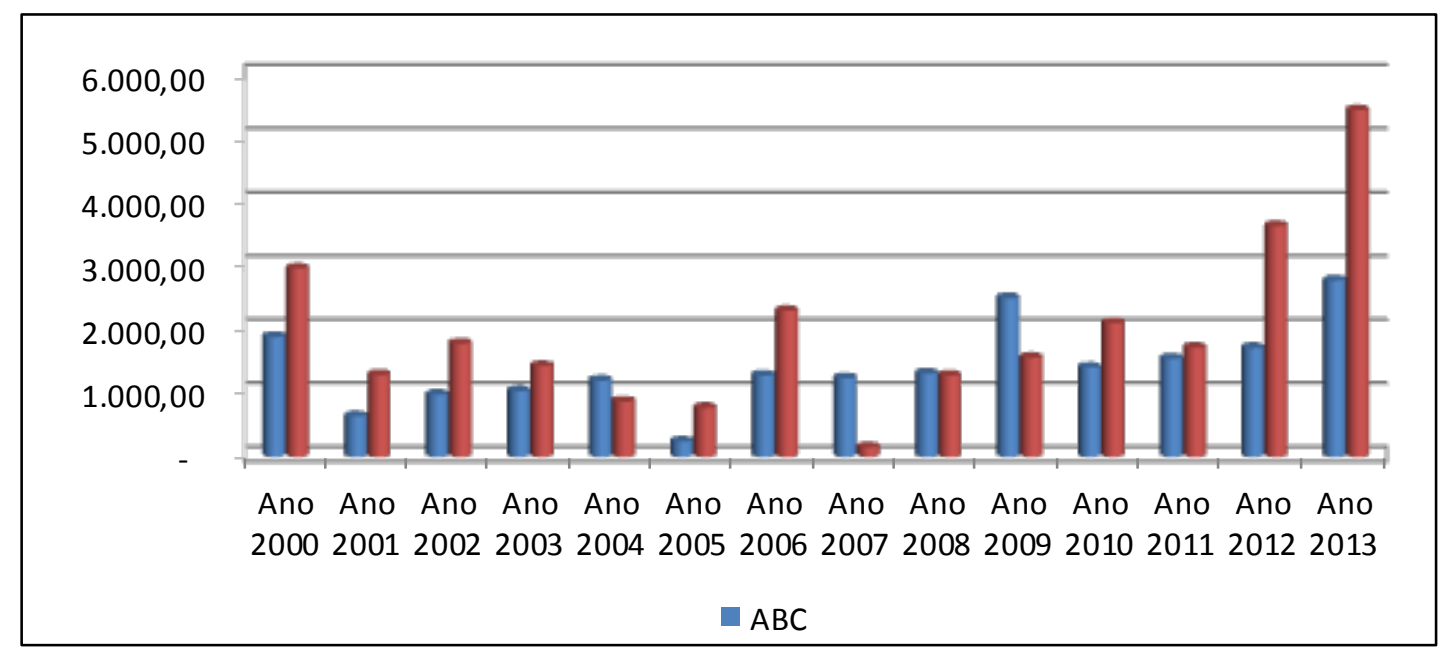

Fonte: PIESP-SEADE, 2013 - elaborado pelo autor

Portanto, com base na análise socioeconômica supra, a indagação acerca das razões pelas quais esta aparente mudança de rota dos investimentos, se coloca presente, de modo a se questionar o papel das instituições sociais de cada região em relação a teoria versus a prática das suas ações, a fim de se obter o adequado planejamento territorial.

\footnotetext{
${ }^{4}$ PIESP-SEADE: instrumento de aferição das tendências de ampliação produtiva bem como de oportunidades de negócio no Estado de São Paulo. A pesquisa contabiliza os anúncios divulgados pela imprensa
} 


\section{AS INSTITUIÇÕES SOCIAIS E O SEU PAPEL NO DESENVOLVIMENTO REGIONAL}

Para fins de delimitação e esclarecimento do conceito de Instituições Sociais empregada neste artigo, discorrer-se-á, tal como sendo as estruturas inseridas na sociedade, cujas características estejam imbuídas de ações coercitivas com autoridade moral, avessas à exterioridade, mas sim, com objetividade e respeito à historicidade. Portanto, tais instituições são inerentes na conjuntura histórica de determinada sociedade; porém, de caráter autônomo e com preponderância no comportamento e atitude sociais.

Poder-se-ia enumerar diversas Instituições Sociais existentes em comum nas regiões da Região do Grande ABC e do Eixo Dutra presentes no convívio social, mas com o intuito de sistematizar o estudo, as instituições aqui analisadas terão um caráter universal; ou seja, aquelas cuja existência seja comum em todas as sociedades, sendo para fins deste estudo, o Estado, a Economia e a Universidade.

Inicialmente, a abordagem do Estado se caracteriza como a de principal importância, sem detrimento das demais, pois deste, emana o papel de regulador das demais instituições, por meio das relações sociais e políticas, bem como a instituição detentora dos mecanismos de controle social. O Estado se faz necessário para direcionar o bom convívio coletivo de uma população que pertença a um território em comum.

Ademais, a administração do Estado se dá por meio dos gestores, os quais tem por obrigação "Garantir a sociedade condições de desenvolvimento econômico-sociopolítico e cultura do cidadão” (GOMES, SILVA, 2012, p. 04). Espera-se do gestor público, a função de executor do papel do Estado; ou seja, com vistas a cidadania e ao social, imerso nos aspectos de direito administrativo e de representação social, com a visão global de gestão, a fim de fundar parcerias com os diferentes setores, por meio de estratégias previamente planejadas com a interação entre os planos, os programas, as metas, bem como com as ações que resultem no desenvolvimento econômico e social.

Uma instituição, de caráter abstrato, mas que sofre diretamente os reflexos das decisões do Estado é a economia, que representa o mercado, decorrente da produção, distribuição e consumo das riquezas territoriais, utilizando os recursos da sociedade criando os seus valores e normas econômicas presentes na vida dos indivíduos.

No âmbito acadêmico, a economia é a ciência que estuda o indivíduo em seu meio social, por meio do seu comportamento ante as demandadas de recursos disponíveis para satisfazê-lo. Destarte, anela obter soluções para os problemas existentes com vistas ao funcionamento dos sistemas econômicos e a correlação de seus agentes (CANO, 1998).

Logo, a Ciência Econômica impulsiona o indivíduo a transformar o seu território social, por intermédio da autocompreensão das suas ações primárias e das suas preferências, as quais são objetos de estudo tanto da macroeconomia, quanto da microeconomia, metamorfoseando a análise comportamental. Assim, o ambiente do desenvolvimento passa a ser objeto de investigação, para que este venha configurar a base para a formulação de políticas públicas.

O desenvolvimento econômico tem sua origem no comportamento humano, que é passível de escolhas, as quais implicam em conflitos que ocorrem devido ao não 
atendimento da demanda, ou não atendidos em sua plenitude, portanto, incapazes de satisfazer o indivíduo e resultam no inexorável fato da "lei da escassez" de recursos. Tal lei prescreve a necessidade de se alocar de forma eficiente os fatores/recursos de produção disponíveis, a fim de se obter bens e serviços, que servirão para atender as necessidades infinitas dos consumidores (RETAMIRO, 2013).

Assim, tal realidade condiciona-se, direta e indiretamente, a um processo econômico que engloba o comportamental de escolhas, fazendo com que uma vez escolhida determinada opção, isso implicará necessariamente na recusa de qualquer alternativa (OLIVEIRA, 2010).

Desta forma, medir o desenvolvimento significa um desafio. Modelos econométricos não atendem a este anelo, pois as políticas endógenas refletem o resultado de seus pressupostos, as quais, por parte do Estado mostram-se limitadas, permitindo a expansão dos conceitos capitalistas, por meio dos conglomerados econômicos que atuam no mundo econômico globalizado, os quais ocasionam problemas sociais, porém locais (VIEIRA, 2009).

No tocante a universidade, esta se coloca como uma das mais importantes instituições sociais. Sua função de promotora do saber está intrinsicamente relacionada à transmissão dos valores sociais e das crenças das culturas humanas. $\mathrm{O}$ ambiente universitário possui a capacidade de transformar o indivíduo, por sua vez a sociedade, conscientizando-o dos seus direitos e deveres, a fim de que este seja um agente transmissor dos conhecimentos desenvolvidos, socializando-os, para perfazer os papeis sociais.

O arcabouço legal que define a importância da educação pode ser analisada conforme reza o Art. $1^{\circ}$ da Lei 9.394/96:

A educação abrange os processos formativos que se desenvolvem na vida familiar, na convivência humana, no trabalho, nas instituições de ensino e pesquisa, nos movimentos sociais e organizações da sociedade civil e nas manifestações culturais (Brasil, Lei 9.394/96, art. $\left.1^{\circ}\right)$.

Cabe ainda ressaltar, o que expressa o parágrafo segundo da mesma Lei, onde afirma que “A educação escolar deverá vincular-se ao mundo do trabalho e à prática social”. Ao que tange o papel das universidades, fica claro o que destaca no Art. 52, da Lei em análise, onde se lê: “As universidades são instituições pluridisciplinares de formação dos quadros profissionais de nível superior, de pesquisa, de extensão, de domínio e cultivo do saber humano (...)”.

Em suma, a universidade possui um papel provocador, pois por meio da ação ensinopesquisa desenvolve a atividade, a qual suscita um determinado problema que provoca o levantamento de dados a partir da formulação de hipóteses, as quais culminam com a experimentação (SAVIANI, 1987, p. 30), perpassando pelas fases de produção do conhecimento a ser vivenciado pelo discente universitário vindo a resultar nas possibilidades de mudança, decorrentes de reflexões teóricas baseando as ações que contribuiriam nos processos de transformações sociais. 
Destarte, tanto a universidade quanto a economia e o Estado, formam o tripé básico para que se pense o planejamento territorial de regiões em fase de formação. Assim, discutirse-á a relação imbricada destas instituições sociais, suas ausências na formatação territorial, bem como a expectativa depositada nestas, com base nas regiões do Grande ABC e do Eixo Dutra.

\section{ANÁLISES E DISCUSSÃO}

As instituições sociais se relacionam de forma sobreposta, quando analisados seus respectivos papéis ante a sociedade. Ao longo da história brasileira, sendo o Estado a instituição responsável por prover o bem estar social e, considerando que isto não se tornou perceptível, se faz necessário repensar suas funções, a fim de volvê-lo como agente na promoção do real desenvolvimento no âmbito econômico mantendo o nível dos fatores de produção relativamente alto, com vistas a potencialidade do país, para se estruturar um planejamento com ideais de cunho democrático. Neste contexto, Furtado (1962), já ressaltava a necessidade das reformas de base, as quais compreendiam a consciência dos problemas estruturais de natureza qualitativa, convergindo para o atendimento dos anseios da população. Contudo, a sensibilidade para as questões voltadas para o bem estar social, foi relegada pelas grandes cidades em detrimento de uma economia industrial, a qual reprime as demandas sociais, se aproveitando da não estruturada sociedade, conforme relata Furtado (1978):

Privados progressivamente de memória histórica e senso de identidade, referidos a um sistema de medidas concebido para os fins da acumulação, os povos atraídos pela via indireta para a civilização industrial, passaram a ser classificados, ordenados, etiquetados, transfigurados em entidades abstratas, cujo comportamento se explica exaustivamente, a partir de um número limitado de dados. (FURTADO, 1978, p. 77)

Adotou-se, portanto, o desenvolvimento sob o pacto de acelerar o processo de acumulação, suplantando os padrões culturais nas regiões metropolitanas, sendo o elemento competitivo, o fator principal, que em aspectos econômicos resultam na criação de condições atrativas para os investimentos diretos estrangeiros, a qual justifica a concentração de renda. Contudo, nenhuma evidência existe, de que a industrialização dependente conduz a formas sociais estáveis (FURTADO, 1977). Denota-se, todavia, que a crescente heterogeneidade social é fruto de um autoritarismo utilizado para proporcionar a rápida acumulação de riqueza regional, associada à repressão das forças sociais não atendidas pelo processo de crescimento industrial, frustrando assim, o real desenvolvimento desejável.

Ressalta-se que este trabalho não participa de que o legado do setor industrial tenha sido totalmente maléfico, mas sim, discute-se o modelo de desenvolvimento aplicado no processo histórico na Região do Grande ABC, o qual pode influenciar o crescimento 
econômico nas cidades do Eixo Dutra, sob a ótica da melhoria da qualidade de vida, pois o crescimento consiste na capacidade de produção de bens e serviços, fator primordial para que haja o desenvolvimento. Entende-se, desta maneira, que o desenvolvimento transcende o crescimento, visto que este não considera somente o aspecto econômico, mas também o cultural e social, tendo em vista que a necessidades sociais obedecem aos singulares aspectos regionais.

Dissemina-se, portanto, um sistema contemporâneo de construção do espaço urbano, no qual o produto da própria indústria de larga escala na cidade se torna um custo para alguns setores geridos pelo Estado. Nisto, se vê a necessidade de estudos que resultem em novos paradigmas de análise urbana, haja vista o detrimento dos fenômenos macrossociais privilegiando o objeto local.

Insere aqui, o papel da universidade, que é o de agir por meio do saber para a difusão do desenvolvimento regional, a fim de minimizar as disparidades socioeconômicas entre as regiões, de forma conjunta com o poder público e o setor produtivo. Porém, a educação não fugiu do cenário de expansão da economia capitalista, frente a isto trouxe junto os problemas de precarização e flexibilização do trabalho para dentro da universidade. A ausência do Estado possibilitou a expansão das universidades privadas, identificando um nicho de mercado com possibilidades lucrativas. Associada ao ideal de que a educação trará o pleno emprego faz com que o consumo por este serviço aumente a passos largos, "cresce, por um lado, a educação privada e, por outro, precariza-se a educação pública, em todos os níveis do ensino.” TAVARES (2011, p. 239).

Corrobora a este pensamento SILVA E CARVALHO (2011) quando explana que na segunda metade da década de 1990 a reforma da educação superior proporcionou um novo modelo de avaliação das instituições caracterizado por uma avaliação produtivista e positivista. Lembra, ainda, da forma de trabalho docente na década de 80 nas universidades publicas: os professores contabilizavam 8 horas de aula com turma de até 20 alunos, as pesquisas eram apoiadas e abrigadas pela própria instituição, os prazos não eram tão rígidos e não tinha a meta de estar em vários periódicos e eventos para publicação. Valorizava-se a função da instituição a de formar novos profissionais.

Não obstante, nas das últimas décadas, não é difícil encontrar em artigos ou nos encontros de intelectuais, um "clamor" entre os docentes pela imposição de serem produtivos. O "ser produtivo" repercute ao trabalhador industrial, a docência deixa de ser um trabalho intelectualizado e criativo, para responder a lógica de mercado se iguala, a função professor universitário ao do operário mecanizado, conforme expressa Saviani “(...) o 'ensino tradicional' se impunha a tarefa de transmitir os conhecimentos obtidos (pela ciência), portanto, já compendiados, sistematizados e incorporados ao acervo cultural da humanidade”. (SAVIANI, 1987, p. 30).

Diante do exposto acima, verifica-se as limitações das instituições sociais analisadas. Tendo em vista as relações imbricadas destas, presumem-se os desafios a ser suplantado pelos municípios do Eixo Dutra, pois o volume de investimentos anunciados na região demandará uma mão de obra não somente com qualificação especializada, mas também, com capacidade de análise crítica capaz de diagnosticar e sanar tais desafios.

Por outro prisma, a oportunidade de inovar o pensamento acerca do planejamento e gestão territorial, se apresenta iminente aos municípios do Eixo Dutra, a fim de coibir um 
eventual esgotamento, ou ao menos, a postergação deste. Tal oportunidade consiste na ação antagônica praticada até então pelo Estado, da qual descreve Klink:

A partir desse prisma, mostrou-se que o Estado brasileiro - embora se observem transformações na forma de sua atuação desde o regime tecnoburocrático centralista, sempre privilegiou um projeto político centrado na produção econômica em detrimento da reprodução social. Isto gerou um espaço metropolitano comprometido pelas contradições socioespaciais e ambientais (KLINK, 2013).

Outrossim, a RMVPLN nasce com o seu planejamento pré-formatado nos moldes da Região do Grande ABC. O adensamento demográfico, bem como a concentração de riqueza gerada pelos municípios, se demonstram como indicadores de uma eventual reprodução de governança metropolitana condizente com as contradições socioespaciais. Renovar o curso de governança metropolitana, com vistas a um planejamento social-desenvolvimentista, que resulte em território planejado com participação social exige a mudança de paradigma, que otimize a densidade demográfica e econômica a fim de minimizar os custos logísticos e com proteção e organização de espaços públicos abertos.

\section{CONSIDERAÇÕES FINAIS}

Neste artigo foi explanado acerca das regiões metropolitanas, mais especificamente, duas subdivisões de RM's distintas, sendo a Região do Grande ABC e a do Eixo Dutra, as quais figuram no cenário econômico com considerável relevância, apesar da diferença temporal existente entre as constituições das respectivas RM’s.

A passagem de um regime tecnoburocrático centralista e autoritário, o qual refutou a governança metropolitana deixando-a aquém das expectativas de um desenvolvimento econômico includente, não apenas no quesito socioeconômico, mas também, ao que tange a participação do indivíduo, a fim de superar a dicotomia centro $x$ periferia.

A criação de uma RM perpassa por um plano metropolitano de ordenamento territorial que transcenda os programas setoriais isolados, mas que integre as demandas de transporte, habitação, saúde, entre outras de forma holística. As demandas sociais exigem a elaboração de políticas públicas não somente de caráter normativo, mas que inove por meio de um planejamento instaurador nas formas de sociabilidade, o que proporcionaria o direito à cidade como um todo.

Lucubrar sobre a sociedade dirige a atentar para a multidisciplinaridade coexistente nela. Romper com os instrumentos clássicos de intervenção das políticas públicas, usufruindo de análises e propostas que condizem com os seus habitantes, a fim de se instituir uma construção permanente.

Uma nova abordagem de gestão pública, subversiva e comunicativa, imbuída de um projeto de sociedade, se torna necessária para a revalorização dos setores da cidade. Isto requer a articulação simultânea das instituições sociais em três campos de ação: politico (Estado), econômico (mercado) e cultural (universidade). Nos campos político e econômico, 
perfilhar as práticas que conjuntam as decisões dos níveis local e global, a fim de reconhecer os problemas urbanos, para então, desembarar-se do dogmatismo.

A crise de cidadania, decorrente da desconcatenação do tripé das instituições sociais, desfaz o sentimento de interesses em torno de projetos comuns que estimulem a própria gestão. Ademais, se faz necessária a insurgência de instrumentos de planejamento territorial, que contemplem uma ampla reforma do pensamento reconhecendo a sociedade local.

Portanto, se torna inexorável a criação de um projeto alternativo, no qual as políticas de planejamento territorial extrapolem as soluções teóricas enraizadas nas políticas tradicionais, a fim de colocar os habitantes do território como prioridade, sob a égide das dimensões de sustentabilidades social, cultural, econômica e institucional, criando mecanismos que estruturem a política urbana transformadora e sustentável de longo prazo.

\section{REFERÊNCIAS}

AGENCIA DE DESENVOLVIMENTO ECONOMICO DO GRANDE ABC. Por dentro do Grande ABC. Santo André. 2014. Disponível em http://www.agenciagabc.com.br/ grandeabc0709br/grande-abc/index.php?id=14, acessado em 24 jul. 2014.

BRASIL. Lei complementar $n^{0} 14$, de 8 de junho de 1973. Estabelece as regiões metropolitanas de São Paulo, Belo Horizonte, Porto Alegre, Recife, Salvador, Curitiba, Belém e Fortaleza. Presidência da República. Casa Civil. Subchefia para Assuntos Jurídicos. Disponível em: http://www.planalto.gov.br/ccivil_03/leis/lcp/Lcp14.htm Extraído em 07 de jul. 2014.

Lei $n^{0}$ 9.394, de 20 de dezembro de 1996. Estabelece as diretrizes e bases da educação nacional. Presidência da República. Casa Civil. Subchefia para Assuntos Jurídicos. Disponível em: http://www.planalto.gov.br/ccivil_03/leis/19394.htm Extraído em 07 de jul. 2014.

CANO, W. Introdução à economia: uma abordagem crítica. São Paulo: Fundação Editora da UNESP, 1998.

FURTADO, C. Prefácio a nova economia política. Rio de Janeiro. Paz e Terra, 1977.

Terra, 1978.

Criatividade e dependência na civilização industrial. Rio de Janeiro: Paz e

GARSON, S. Regiões Metropolitanas: por que não cooperam?. Rio de Janeiro. Ed. Letra Capital. 2009.

GOMES, D.F.S., SILVA.G. Concepção Popular da Função do Gestor Público. In Congresso Norte Nordeste de Pesquisa e Inovação. Palmas. Tocantins. 2012.

IBGE. Censo Demográfico 2010. Disponível em: <http://www.censo2010.ibge.gov.br> .

KLINK, J. Por que as regiões metropolitanas continuam tão ingovernáveis? Problematizando a reestruturação e o reescalonamento do estado social-desenvolvimentista 
em espaços metropolitanos. In: Território metropolitano, políticas municipais : por soluções conjuntas de problemas urbanos no âmbito metropolitano / editores: Bernardo Alves Furtado, Cleandro Krause, Karla Christina Batista de França.- Brasília : Ipea, 2013.

LAGO, L.C. do. O que há de novo na clássica dualidade núcleo-periferia: a metrópole do Rio de Janeiro. In: RIBEIRO, L.C. de Q. (Org.). O futuro das metrópoles: desigualdades e governabilidade. Rio de Janeiro: Revan, Fase, 2000.

LUZ, M. S. MINARI, G.M. SANTOS, I.C. Aglomerações industriais no setor aeroespacial e automobilístico no Vale do Paraíba: uma comparação de trajetórias de formação. Journal of Aerospace Technology and Management. Vol. 2, n. 1, Jan-Apr. 2010. Pág. 71-82. Disponível em:

<http://www.jatm.com.br/papers/vol2_n1/JATMv2n1_p7182_Aglomeracoes_industriais_no _setor_aeroespacial_e_automobilistico_no_Vale_do_Paraiba_Paulista.pdf $>$ Acessado em 07 de dezembro de 2011.

MARICATO, E.. Metrópoles desgovernadas. Estudos Avançados. Estud. av. vol.25 no.71 São Paulo Jan./Apr. 2011. Extraído de: http://www.scielo.br/scielo.php?script=sci_arttext\&pid=S010340142011000100002\&lng=e

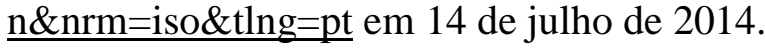

OLIVEIRA, M.E. A economia e o comportamento humano. O Economista. Março 2010. Disponível em: http://www.oeconomista.com.br/a-economia-e-o-comportamento-humano/. Acesso em: 28 de dezembro de 2011.

SEADE. Pesquisa de Investimentos Anunciados no Estado de São Paulo. 1998-2013. Disponível em: http:/produtos.seade.gov.br/produtos/piesp/view/index.php. Acessado em 14 jul. 2014.

RETAMIRO, W., RICCI, F. Estratégia desenvolvimentista no Vale do Paraíba: incubadora de empresas de Jacareí. XIII Mostra de Pós-graduação. INCLUSÃO VERDE: Ciência, Tecnologia e Inovação para o Desenvolvimento Sustentável. 16 a 20 de outubro de 2012.

RETAMIRO, W. Empreendimentos econômicos solidários e o desenvolvimento regional. 2013. 114 f. Mestrado (Planejamento e Desenvolvimento Regional). Universidade de Taubaté. Taubaté. 2013.

RICCI, F. Indústria têxtil na periferia: origens e desenvolvimento - o caso do Vale do Paraíba. Taubaté: Cabral Editora e Livraria Universitária, 2006.

SAVIANI, D. Ensino público e algumas falas sobre universidade. São Paulo. Cortez: Autores Associados, 1987.

VIEIRA, E.T. - Industrialização e políticas de desenvolvimento regional: o Vale do Paraíba Paulista na segunda metade do século XX. 2009. Tese de Doutorado. Universidade de São Paulo - Faculdade de Filosofia, Letras e Ciências Humanas. São Paulo. Brasil. 2009. 